\title{
Wind Turbine Generation System Implemented with a Car Alternator for Use in Isolated Locations
}

\author{
H. Fernández ${ }^{1}$, A. Martínez ${ }^{2}$, V. Guzmán ${ }^{3}$ and M. Giménez ${ }^{3}$ \\ ${ }^{1}$ Unexpo Vice-Rectorado Puerto Ordaz, Departamento Ingeniería Electrónica \\ Centro de Electrónica de Potencia y Accionamientos (CEPAC) \\ hfernandez@poz.unexpo.edu.ve \\ ${ }^{2}$ Universidad de Zaragoza. Centro Politécnico Superior de Ingenieros \\ amiturbe@posta.unizar.es \\ ${ }^{3}$ Universidad Simón Bolívar, Departamento de Electrónica y Circuitos \\ vguzman@usb.ve mgimenez@usb.ve
}

\begin{abstract}
This work presents a wind driven AC electrical generator system for use in isolated locations. The mechanical energy is provided by a vertical axis wind turbine, connected to a standard car alternator. This arrangement requires no mechanical speed control and, as far as possible, can be produced and serviced in many workshops in third word countries, without special tooling and using locally available materials and parts. Controlling the alternator field current a regulated $12 \mathrm{Vdc}$ supply is generated. The $12 \mathrm{Vdc}$ (nominal) output is fed to the power electronic block formed by a chopper upconverter and an inverter stage. Four different output units are available, providing four different quality outputs: a simple non-filtered single phase square wave inverter; a filtered PWM-controlled single phase inverter providing a line-line AC supply $(115 \mathrm{~V} \mathrm{rms}, 60 \mathrm{~Hz}$, for Venezuela); a standard low power UPS; and a filtered PWM-controlled three-phase AC supply (208 V rms, 60 $\mathrm{Hz}$, for Venezuela).
\end{abstract}

This work presents the initial test results, using the alternator and the power electronic blocks, and emulating the wind turbine with an $\mathrm{AC}$ motor.

Key words: Car Alternator, Wind Turbine, DSP synchronous generator.

\section{Introduction}

The continuos trend to use renewable and no contaminant energy supplies for electricity generation is well under way in industrialized countries, mainly in Europe, where it reaches significant levels in several countries (such as Denmark and Spain), but it is not so significant in developing countries, where a high percentage of the world population is concentrated. Since the amount of energy used per capita in those countries is rather low, any improvement in their habitants quality of live,(a highly desirable goal), will necessarily result in a big growth in the demand for traditional contaminant energy supplies, unless a change to renewable and no contaminant energy supplies is started from now on.
There have been many reasons why the developing countries have not started to use renewable and no contaminant energy supplies for electricity generation, the most important being the cost and the lack of technology adaptation. For this reason this work presents the first stage of a modular electricity generation system development based on the use of wind, solar and thermal (from gas produced by biomass) energies, with a low output power level, addressed to small users, dispersed in rural areas (either in isolated farms or in small villages). This system uses car alternators as generating components [1]. This choice can look peculiar given the wide range of electric generators present in the market, but it is made because, at least in Latin America, the widespread use of cars and trucks in all regions means the existence of spare parts supplies and skilled technicians in many localities, while car alternators are locally manufactured in several countries. All this can be used to develop a technological network that will cope with the installation an maintenance of the wind generators. Without this network, the introduction of these renewable and no contaminant energy systems will not be successful, as it has happened till now.

Given the number of different electric generators already offered in the market, at first glance it is not evident why a non standard solution will be best for a low power wind turbine set. Nevertheless, car alternators are very rugged and both they and their spare parts are widely available in third world countries where other electric equipment is hard to find, or in any case, hard to repair. Hence the use of a car alternator as the generator in a wind turbine set for use in isolated third world locations is interesting, providing the other alternator characteristics are adequate for the application.

\section{Car Alternators as Wind Turbine Generators}

The use of a vehicle alternator as the wind turbine generator offers the following advantages: 
1) They are commonly used in widespread applications such as cars, trucks, buses tractors and other farm and industrial vehicles.

2) Great mechanical strength.

3) Spare parts such as windings, rectifier bridges, voltage regulators, bearings, can easily be found in auto part dealers shops, in almost all towns in the world. Also car maintenance workshops, with mechanics able to perform basic maintenance work in this equipment can be found even in otherwise very isolated and backward locations.

4) Wide operating speed range, from 400 RPM to 8000 RPM, and good current generating capability, reaching $320 \mathrm{~A}$ in modern units.

5) Available in a number of standard output voltages: $12,24,32$ or $48 \mathrm{~V}$.

6) A range of matching heavy duty batteries are also widely available, designed to be directly charged from the car alternator.

7) A range of matching (and rugged) integrated output voltage regulators are available in the market.

8) Some special models offer three phase AC outputs.

9) Low unit and spare parts cost.

10) Easy maintenance.

11) Tolerance to wide operating temperature changes without significant performance degradation.

The combination of all these characteristics are particularly interesting when considering the use of car alternators in wind turbine applications in less developed countries, specially in isolated locations.

\subsection{Car Alternator Characteristics}

Car alternators can be selected taking into account their general characteristics, their generation vs. rotational speed curve and the wiring alternatives. The general characteristics of a modern car alternator are as follows [2]:

1) Integrated rectifier with power zener regulation.

2) Diodes set in aluminum heat sinks for high cooling efficiency.

3) Integrated field regulator for constant voltage selfexcitation and simplified installation and service.

4) Long duration brushes protected against dust and dirt.

5) High efficiency integrated blower providing high cooling capacity for extended high load operation.

6) Precisely balanced rotor block for smooth operation and long bearing life.

7) High load ball bearings.

8) Self lubrication with high temperature greases to ensure long ball bearing life.

9) High strength low weight aluminum case.

10) Heavy duty stator winding with high overload capacity.

11) Wide temperature operating range from $40^{\circ} \mathrm{F}$ to $200^{\circ} \mathrm{F}$.

12) Able to operate in both rotating senses.

13) Some models are available in brushless configurations.
14) High power output (50\% of rated) available at low speed.

Alternator operation is characterized by its output current vs. shaft speed curve. Figure 1 presents the current/speed curves measured for three car alternators available in the venezuelan market.

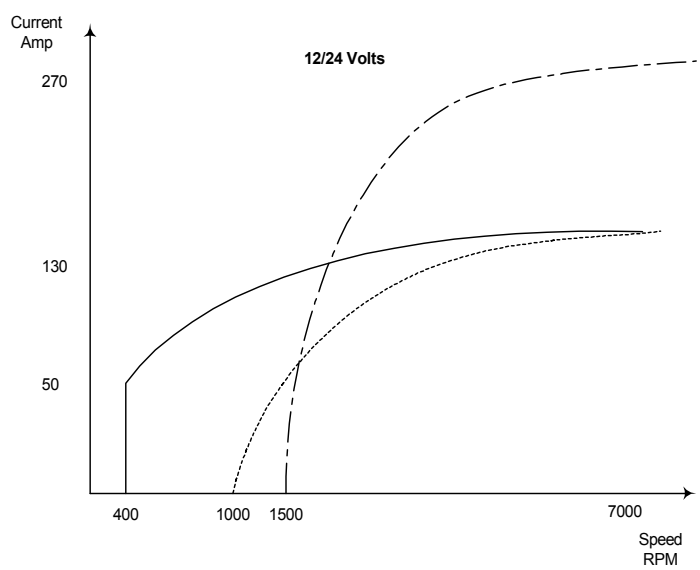

Fig.1. Characteristic current-speed curves measured from three car alternators.

From these curves [2] it is evident that energy generation at low rotational speeds is possible. This is a very important point, since the wind turbine will be a low speed torque source, and a low speed electric generator simplifies the mechanical design, since speed matching between turbine and electric generator can be accomplished with a low relation gear box.

\subsection{Alternator connections}

Alternator connection is dictated by its case terminals. Figure 2 shows the four typical connection configurations in alternators ranging from basic to compact.

Generally the rectifier diode array is integrated in the alternator case, providing a basic dc output. New alternator models incorporate both a field and an output voltage regulators in the same case; old models usually have bigger cases but the electronic regulators are not integrated in the alternator case.

\section{Generation System Description}

Fig. 3 shows the system block diagram. In the test set-up, the car alternator is mechanical coupled to the shaft of a squirrel cage induction motor, which is controlled through an ac drive that simulates the variable speed wind. The variable-frequency voltage generated by the alternator is rectified by an ac/dc uncontrolled converter. This rectified voltage is kept constant by the excitation voltage control of the electric generator. [3]-[4]. 

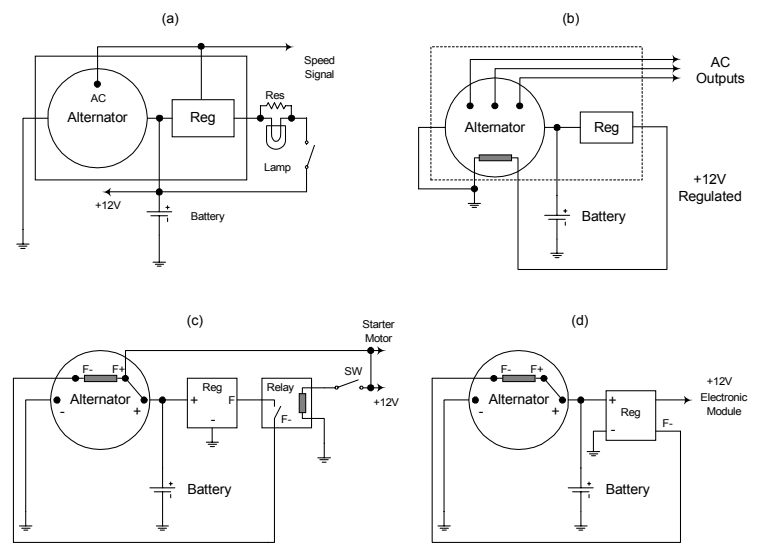

Fig.2 Examples showing possible wiring arrangements, all with integrated output diode rectifier. (a) With field regulator in the alternator case and speed signal (b) With integrated field regulator and $\mathrm{AC}$ outputs for direct connection to power converters. (c) With external regulator - and relay bypass. (d) With external regulator for both field and load.

The rectified alternator voltage can be used in four ways:

1) To directly feed standard 12 volts appliances, and to charge a battery group providing for back-up when no wind is blowing.

2) To feed a square-wave inverter that converts the $12 \mathrm{VDC}$ to $120 \mathrm{VAC}$ square wave.

3) To feed an arrangement of a step-up chopper and a three-phase inverter controlled by a digital signal processor ( DSP TMS320F240 - Texas Instruments), providing a regulated line-quality three-phase output [5].

4) To feed a standard low power UPS, both loading the UPS battery bank and supplying additional output power.

In this application the processing power is provided by a digital signal processor (DSP) model TMS320F240 from Texas Instruments, specially designed to drive a three phase inverter with minimum additional hardware. This DSP is optimized to generate three phase voltages either by Space Vector Pulse Width Modulation (SVPWM) or Third Harmonic Injection (HIPWM). The stored program directly generates the inverter power switches control signals. The carrier waveforms synthesized in the DSP algorithms are given by the following equations:

$$
\begin{aligned}
& u=\frac{1}{\sqrt{3}} m\left[\sin \omega t+\left(\frac{1}{6} \sin 3 \omega t\right)\right]+\frac{1}{2} \\
& v=\frac{1}{\sqrt{3}} m\left[\sin \left(\omega t-\frac{2 \pi}{3}\right) \omega t+\left(\frac{1}{6} \sin 3 \omega t\right)\right]+\frac{1}{2} \\
& \omega=\frac{1}{\sqrt{3}} m\left[\sin \left(\omega t-\frac{4 \pi}{3}\right) \omega t+\left(\frac{1}{6} \sin 3 \omega t\right)\right]+\frac{1}{2}
\end{aligned}
$$

where $m$ is the modulation index, which is continually adjusted to compensate against load changes, variations in the wind driven electric generator output or falls in battery voltage.

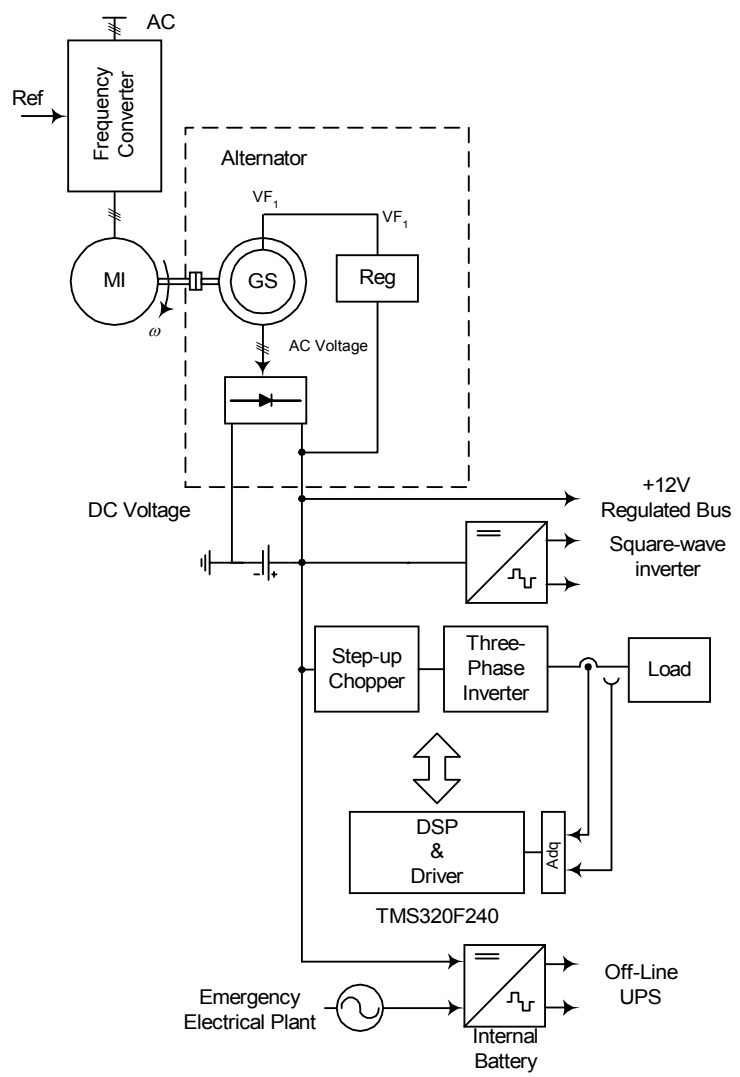

Fig.3. Block diagram of the generation system, showing the four different output paths.

\section{Results}

The electric generator system supplies an useful output from below $200 \mathrm{rpm}$ shaft speed until its maximum 2000 rpm speed. Figure 4a shows the alternator output and the DC regulator field voltage when the speed changes from 500 to $700 \mathrm{rpm}$, and the battery is full charged. As can be observed, the field excitation remains almost unchanged, not affecting the alternator load. Figure $4 \mathrm{~b}$ shows the condition when the battery is discharged or not connected. In this case the regulator output is commutated, generating excitation current harmonics. It is convenient to evaluate the effect of these harmonics over the shaft alternator. If this effect is harmful for the general performance, the control system can be programmed to avoid the commutation mode operation till the battery reaches the appropriate charge level. Figures $4 \mathrm{c}$ and $4 \mathrm{~d}$ present the system performance for single phase loads. Both figures show the output voltage when an square wave inverter is connected, while the alternator is working at 300 and $600 \mathrm{rpm}$ respectively. As can be observed, the output voltage is stable even with significant speed changes.

Next, some tests were performed with the electric generator feeding a DC/DC chopper and an IGBT three phase inverter controlled by the DSP. Figures $4 \mathrm{e}$ and $4 \mathrm{f}$ show the phase to phase voltage and the output current when an induction motor is used as the inverter load. The figures show that these more demanding loads work properly when connected to the electric generator output. 


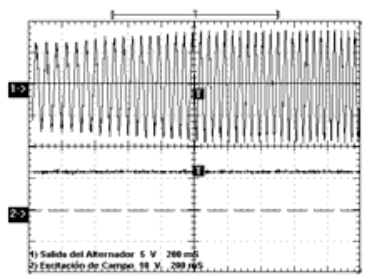

(a)
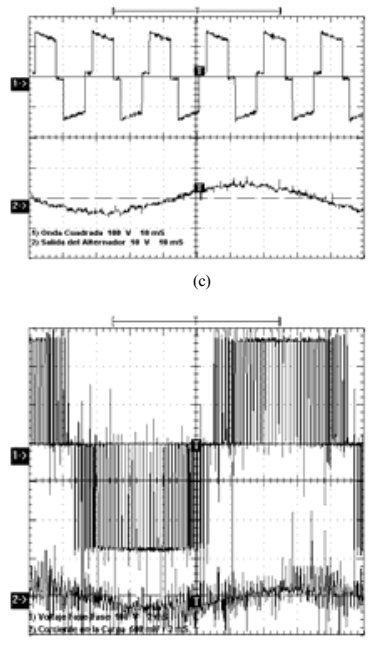

(e)
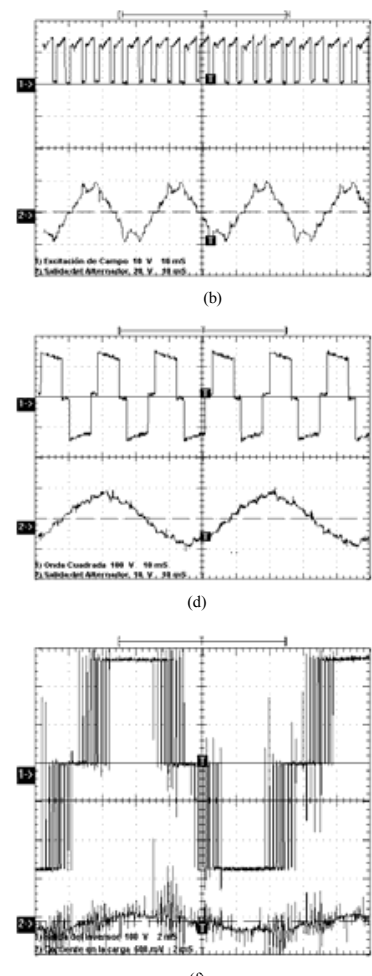

(f)
Fig.4 Experimental output waveforms: (a) - (b) Voltage regulator waveforms; (c) - (d) square wave inverter waveforms; (e) - (f) three phase inverter waveforms.

The electric generator total output power, equal to $2 \mathrm{KW}$ is used in this application, split evenly between the IGBT three-phase inverter and a square wave inverter, each operating at $1 \mathrm{KW}$.The overall system efficiency is about $87 \%$. Finally, figure 5 shows the UPS output voltage when it changes from square wave to sinusoidal (AC line quality), while the electric generator output remains stable thanks to its own regulator.

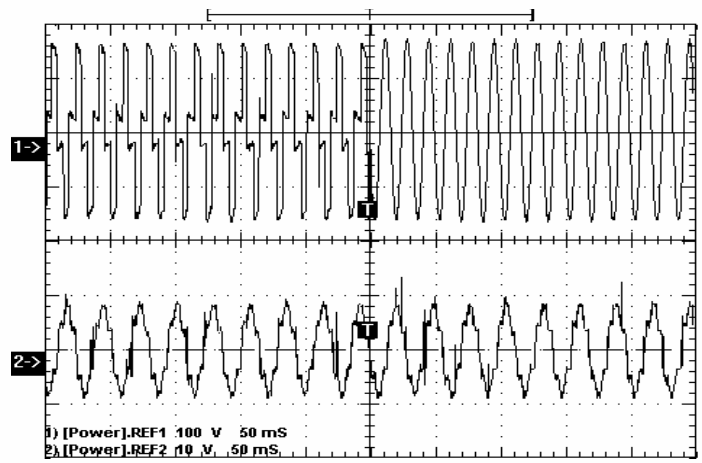

Fig.5 Electric generator output behaviour when UPS output is connected.

\section{Analysis of the electric generator voltage regulator performance}

From the previous experimental results presented in figures $4 \mathrm{a}$ and $4 \mathrm{~b}$, it can be observed that the voltage regulator associated to the electric generator produces modulated pulses which variable duty cycle depends on the battery voltage.

The steady state equations that describe the inductive behavior of the exciter circuit are:

$$
\begin{array}{ll}
V_{s}=R_{a} i_{f}+L_{a} \frac{d i_{f}}{d t}, & 0 \leq t \leq k T \\
0=R_{a} i_{f}+L_{a} \frac{d i_{f}}{d t}, & k T \leq t \leq T
\end{array}
$$

The instantaneous values for each commutation are defined as:

$$
\begin{gathered}
I_{f 0}=\frac{V_{s}\left(e^{k T / T_{a}}-1\right)}{R_{a}\left(e^{T / T_{a}}-1\right)} \\
I_{f 1}=\frac{V_{s}\left(1-e^{-k T / T_{a}}\right)}{R_{a}\left(1-e^{-T / T_{a}}\right)}
\end{gathered}
$$

where $k(0<k<1)$, is the duty cycle, $T_{a}$, and $R_{a}$ are the field circuit time constant and resistance respectively. When the regulator is working in the commutation mode, the generator field current has harmonics that produce pulsating torques in the alternator shaft. Applying Fourier analysis to the voltage waveform, the following expressions are obtained [6]:

$i_{f}(t)=I_{a v}+\sum_{n=1}^{\infty} \frac{A_{n}}{\left|Z_{n}\right|} \sin \left(n \omega_{c} t+\theta_{n}-\phi_{n}\right)$

where

$$
\begin{gathered}
I_{a v}=\frac{V_{a}}{R_{a}} \\
Z_{n}=R_{a}+j n \omega_{c} L_{a}
\end{gathered}
$$

and $Z_{n}$ is the field harmonic impedance. The power delivered by the regulator is:

$$
\begin{gathered}
P_{i}=v_{f}(t) i_{f}(t) \\
=\left\{\begin{array}{l}
V_{a} I_{a v}+I_{a v} \sum_{n=1}^{\infty} A_{n} \sin \left(n \omega_{c} t+\theta_{n}\right) \\
+V_{a} \sum_{n=1}^{\infty} \frac{A_{n}}{\left|Z_{n}\right|} \sin \left(n \omega_{c} t+\theta_{n}-\phi_{n}\right) \\
+\sum_{n=1}^{\infty}\left(\frac{A_{n}^{2}}{\left|Z_{n}\right|} \sin \left(n \omega_{c} t+\theta_{n}\right) \cdot \sin \left(n \omega_{c} t+\theta_{n}-\phi_{n}\right)\right)
\end{array}\right\}
\end{gathered}
$$

In this equation, the right hand expression can be simplified. First, the average pulsating torque is zero, therefore the two first summatories are equal to zero. The 
last double frequency term has an average value equal to zero and its power component can be neglected due to:

$$
n^{2} \omega_{c}^{2} L_{a}^{2}>>R_{a}
$$

Then, the power expression is:

$$
P_{a v}=V_{f} I_{a v}
$$

The alternator fundamental pulsating torque is given by: [6]

$$
T_{e 1}=\frac{3}{2} \frac{P}{2}\left\{L_{m} i_{f r 1} i_{q s}^{r}+\left[\left(L_{d}-L_{q}\right) i_{q s}^{r} i_{d s}^{r}\right]\right\}
$$

where:

$L_{d}$ : direct axis inductance

$L_{q}$ : quadrature axis inductance

$P$ : pole pairs

$L_{m}$ : stator-rotor mutual inductance

$I_{f r 1}$ : fundamental field current

$i_{q s}^{r}:$ Quadrature axis stator current referred to the rotor $\mathrm{c}$

$i_{d s}^{r}:$ Direct axis stator current referred to the rotor

The fundamental field current can be calculated as:

$$
i_{f r 1}=\frac{2 V_{s}}{\pi \sqrt{R_{f}^{2}+\omega_{c}^{2} L_{f}^{2}}} \sin \left(\frac{\omega_{c} k T}{2}\right)
$$

The fundamental field current expressed as a duty cycle function is:

$$
i_{f r 1}=\frac{2 V_{s}}{\pi \sqrt{R_{f}^{2}+\omega_{c}^{2} L_{f}^{2}}} \sin (\pi k)
$$

For a $50 \%$ duty cycle, the fundamental field current and the pulsating torque reach their maximum values. For a $100 \%$ duty cycle, there is no pulsating torque in the turbine shaft. The pulsating torque can be expressed as a fraction of the average load torque, in order to analyze how duty cycle variations affect the pulsating torque, as:

$$
\begin{aligned}
\frac{T_{e 1}}{T_{e}}=\frac{L_{m}\left(\frac{2 V_{s}}{\pi \sqrt{R_{f}^{2}+\omega_{c}^{2} L_{f}^{2}}} \cdot \sin (\pi k)\right) i_{q s}^{r}+\left[\left(L_{d}-L_{q}\right) i_{q s}^{r} i_{d s}^{r}\right]}{L_{m} \frac{V_{a}}{R_{f}} i_{q s}^{r}+\left[\left(L_{d}-L_{q}\right) i_{q s}^{r} i_{d s}^{r}\right]} \\
=\frac{L_{m}\left(\frac{2 R_{f} V_{s}}{\pi \sqrt{R_{f}^{2}+\omega_{c}^{2} L_{f}^{2}}} \cdot \sin (\pi k)\right) i_{q s}^{r}+\left[\left(L_{d}-L_{q}\right) i_{q s}^{r} i_{d s}^{r} R_{f}\right]}{L_{m} V_{a} i_{q s}^{r}+R_{f}\left[\left(L_{d}-L_{q}\right) i_{q s}^{r} i_{d s}^{r}\right]}
\end{aligned}
$$

This equation can be written as a fundamental angle function:

$$
\frac{T_{e 1}}{T_{e}}=\frac{\frac{2 L_{m} V_{s}}{\pi}\left(\cos \phi_{1} \cdot \sin (\pi k)\right) i_{q s}^{r}+\left[\left(L_{d}-L_{q}\right) i_{q s}^{r} i_{d s}^{r} R_{f}\right]}{L_{m} V_{a} i_{q s}^{r}+R_{f}\left[\left(L_{d}-L_{q}\right) i_{q s}^{r} i_{d s}^{r}\right]}
$$

To evaluate the effect of the voltage regulator working in the commutation mode, the test rig presented in Figure 6a was used. The test platform incorporates a vector controlled AC drive which is able to estimate the motor torque (the information is presented as an analog signal in 4-20 mA format). When the system was tested operating with low battery voltage $(10 \mathrm{v})$ or without battery, generator field excitation changed from continuous to pulse mode. Motor torque was measured when the generator operated both in continuous and pulsed excitation current modes. Both torques are presented and compared in Fig.6b, where it is shown that the difference in torque in both operating modes is rather small, as was to be expected from the field current equation presented above (equation).

\section{Conclusions}

1) The initial results obtained in the test platform show that the use of a car alternator as the electric generator in a wind turbine set is technically possible.

2) The initial results obtained in the test platform show that a number of different power conditioning modules can be fed simultaneously from the generator output, tailoring the wind driven system to different load requirements.

3) The initial results obtained in the test platform show that generator performance is not significantly different when operating with continuous or pulsed excitation modes.

4) The initial results obtained in the test platform show that the standard output voltage controller used in the car alternator can be used in the new application. This reduces the control load initially allocated to the DSP controller. Further work will be necessary to explore two consequences of this fact:

A. The possibility of using a lower prized standard microcontroller to replace the DSP, lowering the overall cost of the Wind Turbine Generator (which is a very important design aim).

B. The possibility of allocating new tasks to the DSP, possibly associated with enviromental quality control.

5) Since the initial results obtained in the test platform are encouraging, a complete system prototype will next be design and tested in order to prove if the price and maintenance advantages promised by the use of standard automotive parts are achievable in practice in a Wind-driven Electric Generator aimed at nonspecialized markets in developing countries. 

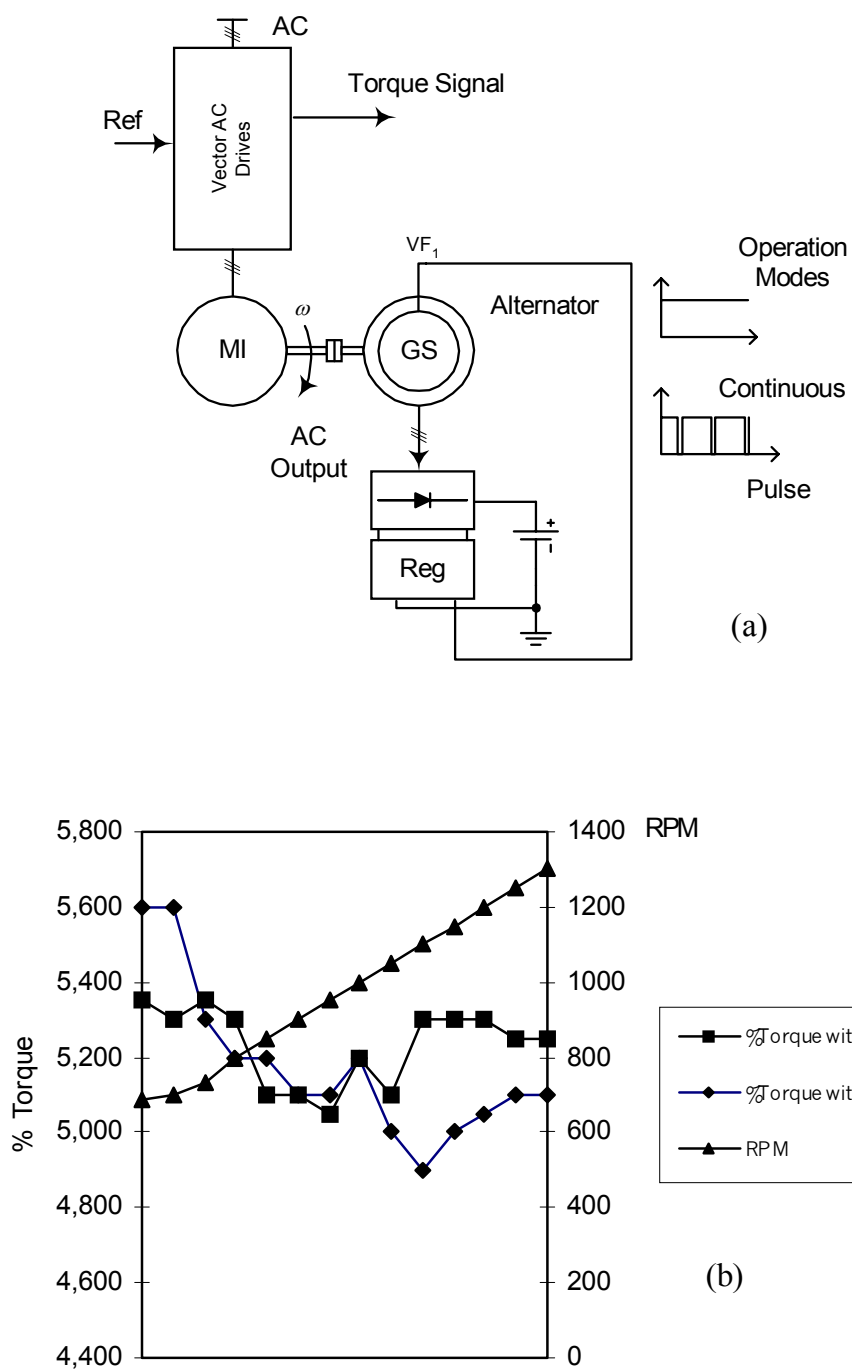

RPM

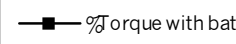

$\longrightarrow$ \%orque without bat.

$\longrightarrow$ RPM

(b)

Fig.6 Test of the generator output voltage control: (a) Test platform with a vector controlled AC drive (b) Torque measured in both operation modes

\section{References}

[1] H. Fernández, A. Martínez, V. Guzmán y M. Giménez. "Aerogenerador implementado con alternador de vehículo para ser usado en emplazamientos aislados". Seminario Anual de Automática y Electrónica Industrial, Vigo, Septiembre 2003.

[2] Prestotlite. Alternator Technical Bulletins Products. www.prestolite.com..

[3] Fernández H, Martínez A, Guzmán V y Giménez M. Sistema de Aerogenerador Implementado con Alternador de Vehículo para ser Usado en Sitios Aislados. III Jornadas de Investigación, Unexpo Puerto Ordaz, Septiembre 2003.

[4] Fernández H, Martínez A, Guzmán V y Giménez M. Aerogenerador Implementado con Alternador de Vehículo para ser Usado en Emplazamiento Aislados. I Encuentro Regional sobre Gestión Energética y Energías Alternativas, Unexpo Puerto Ordaz, Septiembre 2003.

[5] Texas Instruments. Field Oriented Control of 3-Phase AC Motors. BRA073, Europe, Feb.1998.
[6] R. Krishnan. "Electric motor drives, modeling, analysis and control". Prentice Hall. 2001, New Jersey, pp. $145-148$ 